\title{
ISSPIC XV - 15th international symposium on small particles and inorganic clusters
}

\section{Preface}

This special issue of The European Physical Journal D contains contributions solicited from participants of the 15th International Symposium on Small Particles and Inorganic Clusters, ISSPIC XV, held at Oaxaca, Mexico, on September 19-24, 2010. The selection of original research papers in the present issue represents the main topics covered at this symposium.

Many international conferences have emerged in recent years in response to the growing interest in nanoscience and nanotechnology but despite this, since its inauguration in 1976, the biennial ISSPIC symposium continues to be a leading conference in the field of fundamental science of clusters and nanometric structures, as well as in the analysis of finite size effects and their role in bridging the gap from atoms and molecules to the bulk. The originality of ISSPIC among the huge number of nanoscience conferences is that it is focused on very small and model systems where the finite size effects are very important. This is reflected in this special issue, where all submissions were reviewed according to the strict standards of The European Physical Journal regarding scientific novelty, originality, and impact, such that each manuscript accepted for publication represents original cutting-edge research.

The meeting was attended by 145 participants, including 41 graduate students, from 18 countries. In the tradition of ISSPIC meetings there were no parallel sessions and a significant amount of time was devoted to the four lively poster sessions, where 154 posters were presented, a large fraction of them by graduate students. Twenty one invited talks, four of them plenary, were presented. In addition 21 hot topics were selected from the participants' contributions for oral presentations. We therefore believe that ISSPIC XV achieved its goal of enhancing scientific exchange and personal relations amongst its participants.

Although the understanding and control of size dependent behavior still remains the principal challenge in studies of the physics of small particles and clusters, during ISSPIC XV significant progress was reported through various research "hot topics". These include the physicochemical properties of ligand-protected metal clusters, new insights into the catalytically active states of supported metal clusters, and the use of more powerful probes of fundamental cluster properties such as far infrared IR spectroscopy, aberration-corrected scanning transmission electron microscopy and ultrafast time-resolved spectroscopy of a single metal nanoparticle.

One of the sessions of the conference was dedicated to the memory of Professor Tamotsu Kondow and Professor Ekkehard Recknagel. Prof. Kondow (1936-2009) is considered a great pioneer and ambassador in nanomaterials science with important contributions in the study of structure and reactivity of clusters, using mass spectrometry and laser spectroscopy. He also was a distinguished member of the ISSPIC International Advisory Committee. The present special issue is also a tribute to the memory of Prof. Recknagel (1931-2009), a distinguished scientist with important contributions in nuclear physics, hyperfine physics, and cluster science. Prof. Recknagel made pioneering contributions to the science of isolated atomic clusters during the eighties. He chaired ISSPIC V in Konstanz in 1990.

We are grateful to all the members of the International Advisory Committee for their help in the selection of the invited talks. We also thank the members of the National Advisory Committee, the Oaxaca State Local Organizing Committee, and the many people who contributed to the success of this conference. A special acknowledgment is reserved for the sponsoring institutions: Consejo Nacional de Ciencia y Tecnología (CONACYT-México), Coordinación de la Investigación Científica de la UNAM, Red de Nanociencias y Nanotecnología del CONACYT, Gobierno Constitucional del Estado de Oaxaca, Sociedad Mexicana de Física, Centro de Nanociencias y Nanotecnología de la UNAM, and Instituto de Física de la UNAM.

Finally, we specially thank Prof. E. Campbell and Prof. M. Broyer for their help in editing this special issue.

Ignacio L. Garzón (Chairman ISSPIC 15)

Luis A. Pérez, Gabriela Díaz, Cecilia Noguez

Guest Editors 